\title{
EUDRAGIT COATED ALGINATE BEADS BEARING OXALIPLATIN LOADED LIPOSOMES: FORMULATION, OPTIMIZATION AND IN VITRO CHARACTERIZATION
}

\author{
ANKITA TIWARI ${ }^{1}$, SANJAY K. JAIN ${ }^{*}$ \\ 1Pharmaceutics Research Projects Laboratory, Department of Pharmaceutical Sciences, Dr. Harisingh Gour Vishwavidyalaya, Sagar (M. \\ P.), India 470003 \\ Email: drskjainin@yahoo.com
}

Received: 09 May 2021, Revised and Accepted: 20 Sep 2021

\section{ABSTRACT}

Objective: The present investigation aimed to develop and characterize Eudragit S-100 coated alginate beads bearing oxaliplatin loaded liposomes for colon-specific drug delivery.

Methods: Liposomes were formulated by the thin-film hydration method. The process and formulation variables were optimized by Box-Behnken design (BBD) with the help of Design-Expert ${ }^{\circ}$ Software. Three independent variables taken were HSPC: Chol molar ratio $\left(\mathrm{X}_{1}\right)$, hydration time $\left(\mathrm{X}_{2}\right)$, and sonication time $\left(\mathrm{X}_{3}\right)$. The response variables selected were entrapment efficiency of oxaliplatin, polydispersity index, and vesicle size.

Results: The liposomes possessed an average vesicle size of $110.1 \pm 2.8 \mathrm{~nm}$, PDI $0.096 \pm 0.3$, zeta potential of- $6.70 \pm 1.4 \mathrm{mV}$, and entrapment efficiency of $27.65 \%$. The beads were characterized for their size, in vitro drug release, and swelling index. The degree of swelling of the beads was found to be 2.3 fold higher at $\mathrm{pH} 7.4$ than at $\mathrm{pH} 1.2$. The in vitro drug release depicted a sustained drug release in $48 \mathrm{~h}$.

Conclusion: The outcomes of the study proposed that the developed system can be effectively used for site-specific drug delivery to the colon via the oral route.

Keywords: Oxaliplatin loaded liposomes, Formulation, Optimization, In vitro characterization

(c) 2021 The Authors. Published by Innovare Academic Sciences Pvt Ltd. This is an open access article under the CC BY license (https://creativecommons.org/licenses/by/4.0/) DOI: https://dx.doi.org/10.22159/ijap.2021v13i6.43199. Journal homepage: https://innovareacademics.in/journals/index.php/ijap

\section{INTRODUCTION}

Colorectal cancer (CRC) originates from the inner wall of the colon epithelium. It ranks fourth amongst the various malignant tumors. Despite the advancements in its diagnostic methods, it is fatal. Usually, it is marked by the development of colorectal polyps, which are abnormal growths in the intestinal lining. This is followed by its invasion in the muscular tissues and lymph nodes, subsequently to other body organs [1]. Although the treatment of colorectal cancer has greatly improved over time, still it remains one of the leading causes of cancer-related deaths. Oxaliplatin (OHP)-based chemotherapy is the first-line treatment for colorectal cancer [2]. OHP is a third-generation platinum chemotherapeutic drug that can form Pt-DNA adducts with DNA chains to produce inter-chain crosslinking and intra-chain cross-linking, resulting in DNA damage $[3,4]$. It can also inhibit the synthesis of DNA and RNA, and trigger systemic immune reactions, leading to apoptosis [5].

Liposomes are biocompatible, biodegradable, and non toxic. Moreover, liposomes can entrap both hydrophobic and hydrophilic molecules and can release the entrapped drug, therefore it could be a useful drug carrier system [6]. But, they can degrade during their passage via the GIT. This can be prohibited by entrapping them in eudragit coated alginate beads that are degraded by the microflora present in the large intestine. Because of the enteric coating, the beads will remain protected in the GIT, and reach the colon [7]. This approach uses a combination of the $\mathrm{pH}$-sensitive property of enteric polymer (i.e. eudragit S-100) and the biodegradability of alginates for colon-specific targeting. On entering the colon, alginate is degraded by the polysaccharidases and eudragit coating gets dissolved in the ileocaecal region of the small intestine in the colon, releasing the liposomes $[8,9]$.

The developed liposomes were optimized using Box Behnken Design (BBD). BBD is response surface designs based on three-level incomplete factorial designs. They are particularly designed since they need only 3 levels, coded as $-1,0$, and +1 . BBD is available for $3-$ 10 factors. They are formed by combining two-level factorial designs with incomplete block designs. This generates designs with suitable statistical attributes, but most significantly, with only a fraction of the experiments necessitated for a three-level factorial. Since there are only three levels, the quadratic model is appropriate. A comparative analysis of BBD and other response surface designs (central composite, Doehlert matrix, and three-level full factorial design) has portrayed that the BBD and Doehlert matrix are somewhat more efficient than the central composite design but much more efficient than the three-level full factorial designs where the efficiency of one experimental design is termed as the number of coefficients in the estimated model divided by the number of experiments performed [10].

One more advantage of the BBD is that it does not have combinations for which all factors are simultaneously at their highest or lowest levels. Therefore, these designs help to evade experiments conducted under extreme conditions, for which undesirable outcomes may be obtained.

The primary aim of this research work was to optimize the various process and formulation variables to prepare colon-specific oxaliplatin-loaded liposomes for colon cancer delivery.

\section{MATERIALS AND METHODS}

Oxaliplatin was procured as a gift sample from Khandelwal Laboratories Ltd. (Mumbai, India), Hydrogenated soy phosphatidylcholine (HSPC); Cholesterol $(\mathrm{CH})$ was obtained from Sigma (St. Louis, MO). Eudragit S-100 was obtained as a gift sample from Rohm GmbH and Co KG., Darmstadt, Germany, Methanol (Merck Life Science Pvt. Ltd., Mumbai; India), chloroform (Merck Life Science Pvt. Ltd., Mumbai; India), ultrapure water (Millipore, Bedford, MA) was used throughout the experiment. All other chemicals employed were of the highest grade commercially available.

\section{Preparation of liposomes}

Liposomes were formulated by the thin-film hydration method reported by Bangham et al. and Mezei and Gulasekhelam. In brief, HSPC and CH were dissolved in chloroform: methanol (3:1) in a round-bottomed flask. A thin film was formed on the inner sides of the flask by evaporating the solvent system at $45^{\circ} \mathrm{C}$ by continuously 
rotating the round bottom flask for $40 \mathrm{~min}$ at $100 \mathrm{rpm}$ using a rotary evaporator (Buchi type, York Sci Co., Bombay) under reduced pressure. The solvent was completely removed. OHP was dissolved in HEPES buffer ( $\mathrm{pH}$ 7.4). The film was hydrated with the drug-containing HEPES buffer by vortexing the flask for 30 min to get multilamellar vesicles. The suspension was kept aside for $4-5 \mathrm{~h}$ for the complete swelling of the liposomes. It was sonicated for $5 \mathrm{~min}$ at $4 \pm 1{ }^{\circ} \mathrm{C}$. The liposomes were passed through Sephadex G-50 columns to remove the unentrapped drug $[11,12]$.

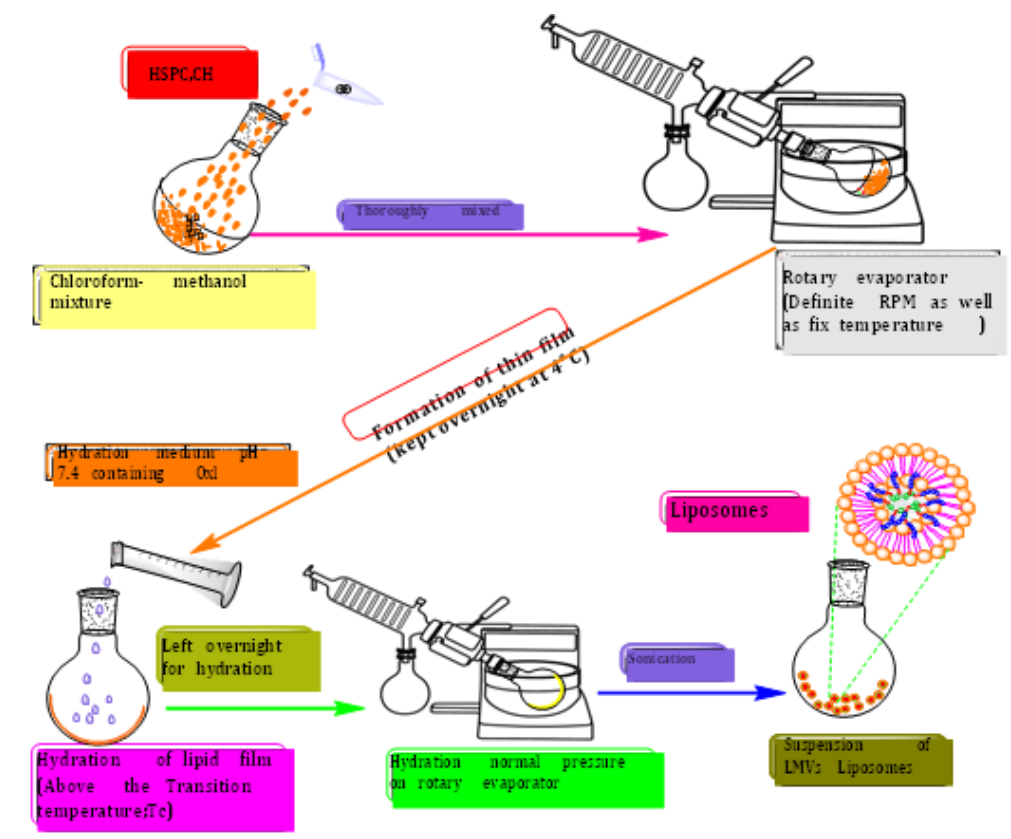

Fig. 1: Schematic representation of formulation of liposomes using the thin-film hydration method

\section{Optimization}

Design of experiment (DoE) is helpful in the identification of main variables influencing the quality characteristics of interest in the process. A designed experiment is a sequence of tests in which the input variables of a process are altered purposefully so that corresponding changes in the output responses can be observed and identified. It is widely employed in the research and development domains for process optimization [13].

Systematically DoE optimization principle was implemented by response surface methodology (RSM) for analyzing second-order polynomial models, using various feasible experimental runs. With the help of Design-Expert ${ }^{\circledR}$ software (10.0, Stat-Ease Inc., Minneapolis, USA) and 3-factors, 3-levels BBD was utilized for analyzing the effect of independent variables i.e. Molar ratio of HSPC: Chol $\left(\mathrm{X}_{1}\right)$, Hydration time $\left(\mathrm{X}_{2}\right)$, and sonication time $\left(\mathrm{X}_{3}\right)$ to estimate the 3-D response surfaces by scrutinizing the effect of independent variables on selected dependent variables i.e., percent entrapment efficiency OHP $\left(\mathrm{Y}_{1}\right)$, polydispersity index (PDI) $\left(\mathrm{Y}_{2}\right)$ and vesicle size $\left(\mathrm{Y}_{3}\right)$. All independent variables are shown as $+1,0$, and-1, which portray high, medium, and low levels, respectively (table 1). All the independent and dependent (response) variables have been outlined with their coded and decoded levels in table 1 . In the design matrix 17 runs were produced on Threelevel, Three-factors (table 2). Few model parameters such as multiple correlation coefficient $\left(\mathrm{R}^{2}\right)$, adjusted multiple correlation coefficient/(adjusted $\mathrm{R}^{2}$ ), predicted multiple correlation coefficient (predicted $\mathrm{R}^{2}$ ), coefficient of variation (CV), and predicted residual sum of the square were estimated and compared to explore the generated model. The response surface analysis (RSA) was carried out by $3 \mathrm{D}$ response surfaces (fig.) using Design-Expert ${ }^{\circledR}$ software (10.0, Stat-Ease Inc., Minneapolis, USA). 3D response surface plots help to establish desirable responses and operating conditions. They usually display a three-dimensional view that can impart a clear image of the response. These 3D surface plots aid the experimenters to comprehend the nature of the relationship between the factors and the responses [14].

\section{Characterization of optimized liposomes}

The optimized liposomes were characterized for various attributes such as morphology, vesicle size, zeta potential, PDI, in vitro assessment.

\section{Surface morphology}

The morphology of the liposomes was determined by transmission electron microscopy (JEM-200 CX; JEOL, Tokyo, Japan). The samples were placed on a grid by the drop-casting technique. It was dried and observed under a transmission electron microscope [15] (fig. 6B).

Table 1: Factors and their levels as per BBD for optimization of liposomes

\begin{tabular}{|c|c|c|c|}
\hline \multirow[t]{2}{*}{ Factors (Independent variables) } & \multicolumn{3}{|l|}{ Levels } \\
\hline & Low $(-1)$ & Medium (0) & High (+1) \\
\hline X1 Molar ration of HSPC: Chol & $1.5: 0.5$ & $2: 1$ & $2.5: 1.5$ \\
\hline X2 Hydration time (Minutes) & 60 & 120 & 180 \\
\hline X3 Sonication time (Minutes) & 6 & 7 & 8 \\
\hline Response (Dependent variables) & Constraints & & \\
\hline R1: Entrapment efficiency OHP & Maximum & & \\
\hline R2: Polydispersity index (PDI) & Minimum & & \\
\hline R3: Vesicular size (nm) & In range & & \\
\hline
\end{tabular}


Table 2: Design matrix with compositions of liposomal formulations

\begin{tabular}{|c|c|c|c|c|c|c|}
\hline \multirow[t]{2}{*}{ Runs } & \multirow{2}{*}{$\begin{array}{l}\text { Factor } 1 \\
\text { Molar ratio HSPC: Chol }\end{array}$} & \multirow{2}{*}{$\begin{array}{l}\text { Factor } 2 \\
\text { Hydration time }\end{array}$} & \multicolumn{2}{|l|}{ Factor 3} & \multicolumn{2}{|c|}{ Responses } \\
\hline & & & Sonication time & \%ЕE ОНP & PDI & Vesicle size \\
\hline 1 & -1.00 & 0.00 & -1.00 & 24.55 & 0.218 & 116.6 \\
\hline 2 & 1.00 & 1.00 & 0.00 & 28.00 & 0.172 & 115.8 \\
\hline 3 & -1.00 & 0.00 & 1.00 & 20.99 & 0.115 & 108.5 \\
\hline 4 & -1.00 & 1.00 & 0.00 & 24.44 & 0.192 & 111.0 \\
\hline 5 & 0.00 & 0.00 & 0.00 & 28.50 & 0.099 & 111.6 \\
\hline 6 & 1.00 & -1.00 & 0.00 & 26.60 & 0.092 & 113.0 \\
\hline 7 & 0.00 & 0.00 & 0.00 & 27.90 & 0.079 & 112.8 \\
\hline 8 & 0.00 & 0.00 & 0.00 & 28.72 & 0.085 & 112.2 \\
\hline 9 & 0.00 & 0.00 & 0.00 & 29.22 & 0.084 & 112.3 \\
\hline 10 & 0.00 & -1.00 & -1.00 & 28.21 & 0.166 & 119.4 \\
\hline 11 & 0.00 & -1.00 & 1.00 & 23.60 & 0.096 & 112.0 \\
\hline 12 & 0.00 & 1.00 & -1.00 & 29.40 & 0.248 & 121.0 \\
\hline 13 & 1.00 & 0.00 & -1.00 & 28.59 & 0.175 & 120.0 \\
\hline 14 & -1.00 & -1.00 & 0.00 & 22.35 & 0.125 & 112.9 \\
\hline 15 & 1.00 & 0.00 & 1.00 & 25.80 & 0.093 & 111.3 \\
\hline 16 & 0.00 & 0.00 & 0.00 & 28.58 & 0.089 & 112.1 \\
\hline 17 & 0.00 & 1.00 & 1.00 & 27.38 & 0.136 & 111.1 \\
\hline
\end{tabular}

\section{Size, zeta potential, and PDI}

Vesicle size (z-average), size distribution (polydispersity index), and zeta potential of drug-loaded liposomes were determined by NanoPlus-3 (Version 5.01, Micromeritics Instrument Corporation, Particulate Systems, Norcross, GA, USA) by Photon Correlation Spectroscopy (PCS). Diluted preparation was placed in the cuvette and size was determined. The zeta potential of the liposomes was computed by HelmholtzSmoluchowski equation from their electrophoretic mobility at $20 \mathrm{~V} / \mathrm{cm}$ field strength and $50 \mu \mathrm{s} / \mathrm{cm}$ conductivity [15].

\section{Entrapment efficiency}

The entrapment efficiency of prepared liposomes was estimated by separating the unentrapped drug with the help of Sephadex G-50 minicolumn by centrifugation technique [16]. Sephadex G-50 (1.0 g) was allowed to swell in $0.9 \% \mathrm{NaCl}$ at $25{ }^{\circ} \mathrm{C}$ with shaking, for $4 \mathrm{~h}$, leading to the gel formation. It was stored at $4{ }^{\circ} \mathrm{C}$ and filled in minicolumn. Liposomes were added to the prepared column and centrifuged at $2000 \mathrm{rpm}$ for $2 \mathrm{~min}$. The separated liposomes were lysed using $0.1 \%$ Triton $\mathrm{X}-100$ and filtered via a 0.2 -micron membrane filter. The filtrate was assessed for drug content using HPLC (Shimadzu Corporation, Kyoto, Japan) employing $0.15 \mathrm{~mol} / \mathrm{l}$ sodium dodecyl sulphate (SDS) $/ 6 \%(\mathrm{v} / \mathrm{v})$ pentanol mobile phase at a detection wavelength of $325 \mathrm{~nm}$. The experiment was performed in triplicate [17]. The percentage entrapment efficiency was calculated using the following formula:

Entrapment efficiency (\%)

$$
=\frac{\text { Total drug }(\mathrm{mg})-\text { free drug }(\mathrm{mg})}{\text { Total drug }(\mathrm{mg})} \times 100
$$

Preparation of liposomes loaded eudragit s-100 coated calcium alginate beads

Liposomes were pelleted by centrifugation, suspended in water, and mixed with alginate solution. This dispersion was passed through a syringe (22 gauge) into the calcium chloride solution $(100 \mathrm{mmol} / \mathrm{l})$ with slow stirring for an hour. The beads formed were collected and washed with distilled water, and dried in a vacuum desiccator overnight to attain a constant weight [18]. The enteric coating of the beads was done as per the method given by Huyghebaert et al. [19]. The coating solution was prepared by stirring Eudragit-S 100 and $1 \mathrm{M}$ ammonia for 1 hour. Then triethyl citrate was added to the solution and stirred for 1 hour. The coating solution was passed by a $0.3 \mathrm{~mm}$ sieve before use. The alginate beads were dip-coated and air-dried.

Physical characterization of liposomes loaded eudragit coated alginate beads

\section{Determination of the size of beads}

The size of uncoated and coated alginate beads was determined using optical microscopy. The diameters of beads were measured with an eyepiece micrometre on an optical microscope (40X. magnification). Randomly 100 selected beads were measured for each sample [20].

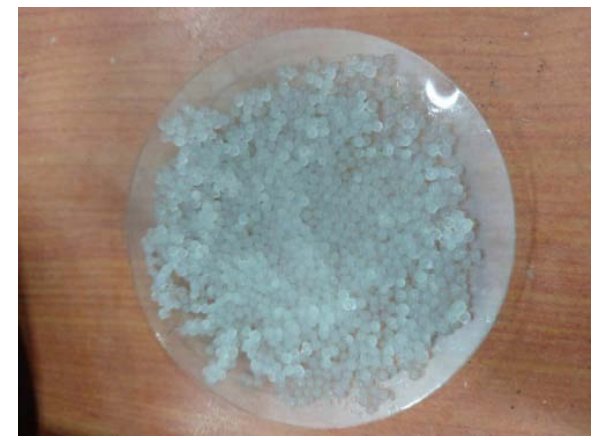

Fig. 2: Liposomes loaded eudragit coated alginate beads

\section{Drug content}

Approximately $0.5 \mathrm{~g}$ of alginate beads were ground in a pestle. The powder was dissolved in $100 \mathrm{ml}$ of phosphate buffer $(\mathrm{pH}$ 7.4) containing $0.1 \%$ Triton $\mathrm{X} 100$ by stirring for $6-7 \mathrm{~h}$. The solution was filtered through a $0.2 \mu \mathrm{m}$ millipore membrane filter [21]. The concentration of the drug was determined by HPLC method as discussed above.

\section{In vitro drug release profile}

In vitro drug release from coated beads was estimated according to Souder and Ellenbogen extraction method [22].

The in vitro drug release was performed in the simulated gastric fluid $\mathrm{pH} 1.2$ in the $1^{\text {st }}$ hour, a mixture of simulated gastric and intestinal fluid $\mathrm{pH} 4.5(2-3 \mathrm{~h})$, simulated intestinal fluid $\mathrm{pH} 7.5$ (4$5 \mathrm{~h})$, and simulated colonic fluid $\mathrm{pH} 6.8(6-8 \mathrm{~h})$ using a dialysis bag [17]:

An accurately weighed amount of enteric-coated beads were placed in a dialysis bag which was placed in a beaker having $100 \mathrm{ml}$ of simulated fluids at $37 \pm 1{ }^{\circ} \mathrm{C}$ with magnetic stirring maintained under sink conditions, and media were changed as per Souder and Ellenbogen's scheme. Samples from the beaker (one ml each) were withdrawn and replaced immediately with the same volume of fresh medium at fixed times. The study was continued for $48 \mathrm{~h}$. These samples were analyzed for drug content using HPLC method as discussed above.

\section{Swelling study}

The swelling behavior of coated and uncoated alginate beads was estimated in buffer solutions of $\mathrm{pH} 1.2$ and 7.4 at $37 \pm 1{ }^{\circ} \mathrm{C}$. The beads 
were accurately weighed $\left(\mathrm{W}_{0}\right)$ and immersed in $100 \mathrm{ml}$ of buffer solution. At definite time intervals, the swollen beads were wiped with tissue paper and weighed (Wg) [23]. The percentage swelling degree of the beads was computed by the equation:

$$
\% \text { Swelling }=\frac{\mathrm{W}_{\mathrm{g}-} \mathrm{W}_{\mathrm{o}}}{\mathrm{W}_{\mathrm{o}}} \times 100
$$

where, $\mathrm{W}_{0}$ is the initial weight of the beads and $\mathrm{Wg}$ is the weight of the alginate beads at equilibrium swelling.

\section{RESULTS}

The developed liposomes were investigated for dependent variables like \%EE of OHP $\left(\mathrm{Y}_{1}\right)$, PDI $\left(\mathrm{Y}_{2}\right)$, and vesicle size $\left(\mathrm{Y}_{3}\right)$ on the chosen independent variables, HSPC: Chol molar ratio $\left(\mathrm{X}_{1}\right)$, hydration time $\left(\mathrm{X}_{2}\right)$, and sonication time $\left(\mathrm{X}_{3}\right)$ as per BBD. The ten polynomial coefficients $(\beta 1-\beta 10)$ were suggested during mathematical modelling, with $\beta 0$ as intercept has been shown in table 3 . All the polynomial coefficients were compliant with the second-order quadratic polynomial model for the assessment of the chances of remarkable interaction(s) between the examined responses as portrayed in the equation.

$$
\mathrm{Y}=\beta_{0}+\beta_{1} \mathrm{X}_{1}+\beta_{2} \mathrm{X}_{2}+\beta_{3} \mathrm{X}_{3}+\beta_{4} \mathrm{X}_{1} \mathrm{X}_{2}+\mathrm{B}_{5} \mathrm{X}_{1} \mathrm{X}_{3}+\mathrm{B}_{6} \mathrm{X}_{2} \mathrm{X}_{3}+\beta_{7} \mathrm{X}_{1} \mathrm{X}_{2} \mathrm{X}_{3}+\beta_{8} \mathrm{X}_{1} \mathrm{X}_{2}\left(\mathrm{X}_{1}-\mathrm{X}_{2}\right)
$$$$
+\beta_{9} X_{1} X_{3}\left(X_{1}-X_{3}\right)+\beta_{10} X_{2} X_{3}\left(X_{2}-X_{3}\right)
$$

A high significant statistical value $(p>0001)$ was achieved for the three response variables in the generated model. The $\mathrm{r}^{2}$ values for all the models were found in the range 0.9875 and 0.9951 which proposed an excellent fit of polynomial equation produced for response data $(\mathrm{p}<0.0001$ in all the cases). The "lack of fit", ranging between $\mathrm{p}=0.6371$ and $\mathrm{p}=0.7335$ for all the produced models were noticed to be insignificant which affirm that the suggested model was appropriate. The closeness of magnitude in the adjusted (Adj) and predicted (Pred) $\mathrm{r}^{2}$ (ranging from 0.9833-0.9888 and 0.92320.9746 ) also confirm an excellent fit of the data to the generated models.

Table 3: Generated model summary statistics of all responses determined according to BBD

\begin{tabular}{llll}
\hline Coefficient code & \multicolumn{2}{l}{ Polynomial coefficients for the response variable } \\
\cline { 2 - 3 } & \% EE OHP & Hydration time & Vesicular size \\
\hline$\beta_{0}$ & +28.58 & +0.087 & +112.20 \\
$\beta_{1}$ & +2.08 & -0.0147 & +1.39 \\
$\beta_{2}$ & +1.06 & +0.033 & +0.20 \\
$\beta_{3}$ & -1.62 & -0.045 & -4.26 \\
$\beta_{4}$ & -0.17 & -1.11 & +1.17 \\
$\beta_{5}$ & +0.19 & +0.71 & -0.15 \\
$\beta_{6}$ & +0.65 & -0.015 & -0.63 \\
$\beta_{7}$ & -2.70 & -0.023 & -0.40 \\
$\beta_{8}$ & -0.54 & +0.034 & +1.37 \\
\hline 9
\end{tabular}

\begin{tabular}{|c|c|c|c|}
\hline \multirow[t]{2}{*}{ Factors (Independent variables) } & \multirow[t]{2}{*}{ Goal } & \multicolumn{2}{|l|}{ Levels } \\
\hline & & Low (-1) & High (+1) \\
\hline $\mathrm{X}_{1}$ Molar ratio of HSPC: Chol & In range & $1.5: 0.5$ & $2.5: 1.5$ \\
\hline $\mathrm{X}_{2}$ Hydration time & In range & 60 & 180 \\
\hline $\mathrm{X}_{3}$ Sonication time & In range & 6 & 8 \\
\hline \multicolumn{4}{|l|}{ Response (Dependent variables) } \\
\hline $\mathrm{Y}_{1}$ : Entrapment efficiency OHP & Maximum & 20.990 & 29.400 \\
\hline $\mathrm{Y}_{2}: \mathrm{PDI}$ & Minimum & 0.079 & 0.250 \\
\hline $\mathrm{Y}_{3}:$ Vesicular size (nm) & In range & 108.500 & 121.000 \\
\hline
\end{tabular}

Table 4: Constraint for numeric optimization and predicted solution

\section{DISCUSSION}

The present study was aimed at developing and optimizing oxaliplatin-loaded liposomes and entrapping them in Eudragit S-100 coated beads that could be used for colonic delivery. OHP-loaded liposomes were prepared by thin-film hydration method using Hydrogenated phosphatidylcholine and cholesterol. OHP is hydrophilic thus; it was entrapped in the aqueous core surrounded by a lipid bilayer of HSPC and cholesterol rendering its structural stability. The optimization of various formulation and process variables was done using Quality by design approach, Designexpert $\AA$ software. The Box-Behnken design was applied for the optimization of formulation and process parameters, namely the molar ratio of HSPC: Chol, Hydration time, and sonication time. It was found that with an increase in the molar ratio of HSPC: Chol, a rise in EE (\%) of OHP was noticed up to a high level, followed by a constant value which could be due to saturation of all the aqueous fluid of the aqueous core [24]. Likewise, increasing the hydration time was accompanied by an increase in the EE (\%) which could be the result of the high amount of the entrapment of aqueous fluid. However, with an increase in sonication time, there was a decrease in the EE (\%) which can be because of the drug leakage due to rupture of liposomes during sonication [25] (fig. 3A-C). Fig. 4 A-C depict the dependence of PDI on various factors like the molar ratio of HSPC: Chol, hydration time, and sonication time. At a low ratio of HSPC: Chol, high PDI was noticed. With an increase in HSPC: Chol ratio and sonication time there was a decrease in PDI. Nevertheless, with an increase in hydration time, there was an increase in PDI. Fig. $5 \mathrm{~A}-\mathrm{C}$ show the dependence of the vesicular size of liposomes on the factors like the molar ratio of HSPC: Chol, hydration time, and sonication time. They show that as the molar ratio of HSPC: Chol and hydration time increased, the particle size also increased. This could be due to the increased bilayer molecules and hydration fluid in the liposomes. While an increase in sonication time led to a decrease in vesicular size because of the high shear stress, which resulted in the rupturing liposomes into smaller vesicles [26].

The optimum preparation has a maximum \% EE of OHP, minimum

$\mathrm{PDI}$, and vesicle size in range $\mathrm{Y} 1=(20.990 \leq 29.400), \mathrm{Y} 2=$ $(0.079 \leq \mathrm{Y} \leq 0.250)$ and $\mathrm{Y} 3=(108.5 . \leq \mathrm{Y} \leq 121.0)$

The morphology of liposomes was confirmed by optical microscopy and transmission electron microscopy images (fig. 6A and $\mathrm{B}$ ). The spherical shape of the vesicles was revealed by transmission electron microscopy. The mean diameter of the liposomes was found to be $110.1 \pm 2.8 \mathrm{~nm}$. Low polydispersity index, i.e. $0.096 \pm 0.3$ showed that liposomes had a narrow size distribution and were homogeneously distributed. Zeta potential is one of the most important attributes to assess the stability of a liposomal suspension, which was found to be$6.70 \pm 1.4 \mathrm{mV}$. The liposomes were entrapped in sodium alginate beads which were further coated with Eudragit S-100. Tri-ethyl citrate was used as a plasticizer during coating due to its good affinity for eudragit. The mean diameters of the uncoated and coated beads were found to 
be $1.375 \pm 0.106 \mathrm{~mm}$ and $1.608 \pm 0.113 \mathrm{~mm}$, respectively. The increase in the size of the coated beads could be attributed to the application of eudragit S-100 coating on the beads. The drug content was in

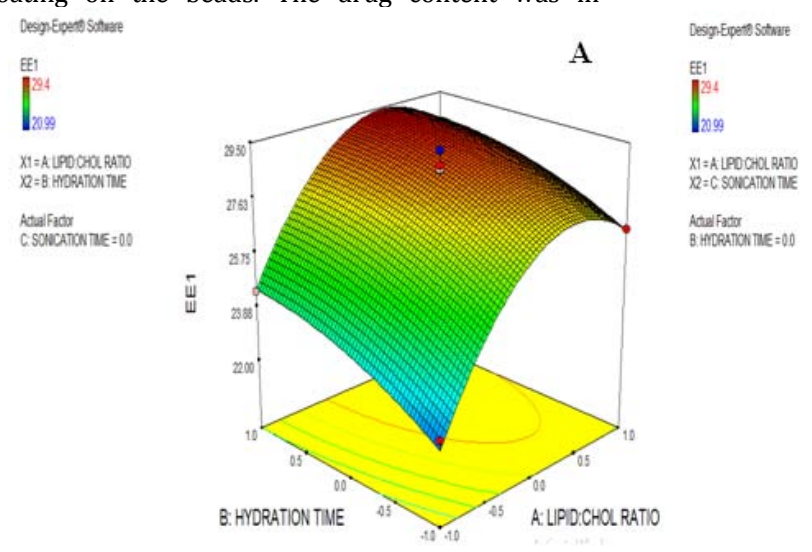

proportion to that of loaded drug ranging from $21 \% \pm 1.8 \%$ to $28 \% \pm 2.7 \%$ wt/wt [27].
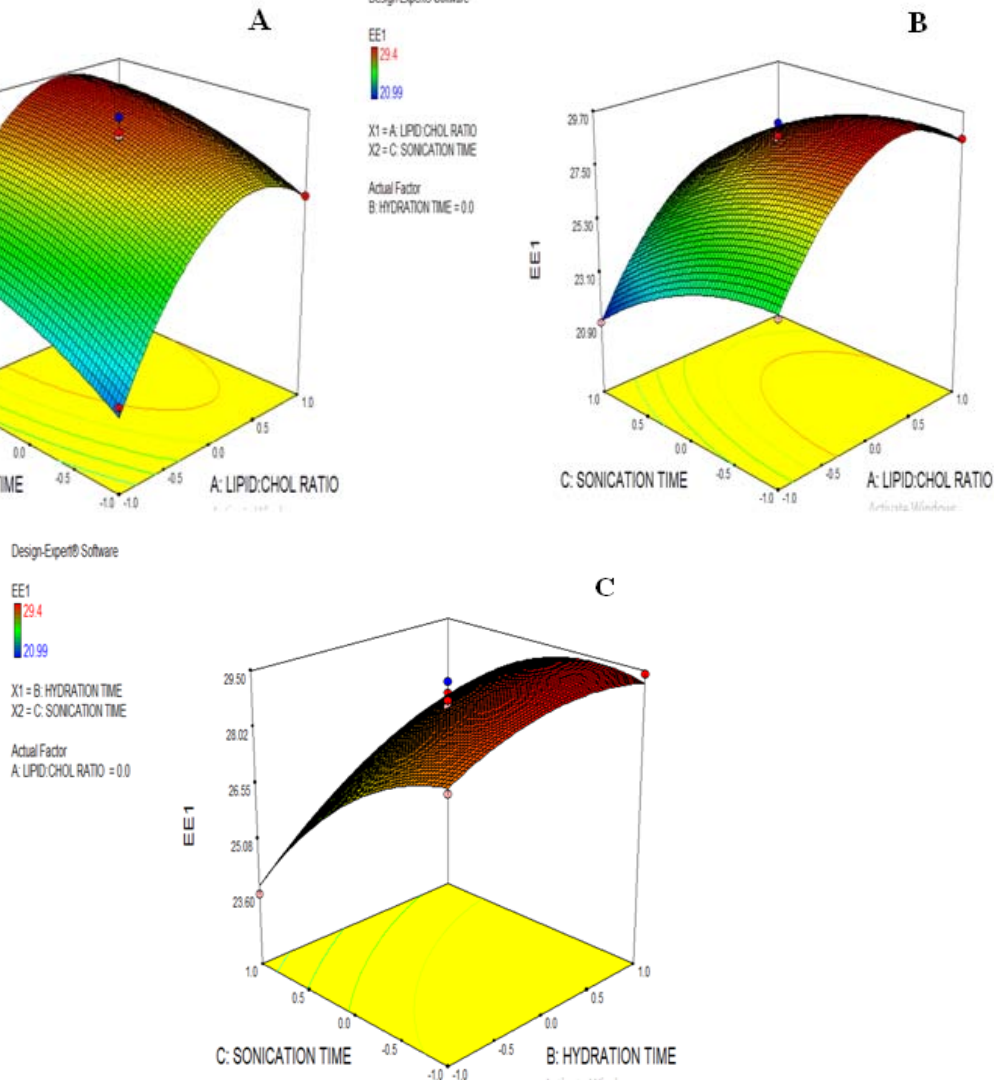

Fig. 3: (A-C) shows the 3-D response surfaces for Entrapment efficiency (EE) of OHP
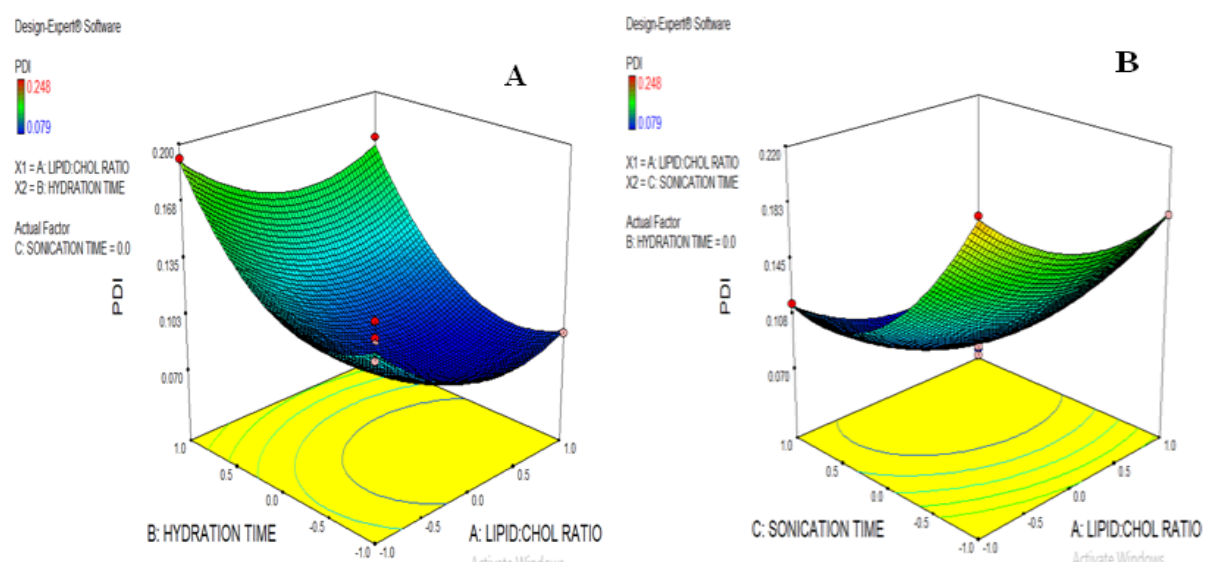


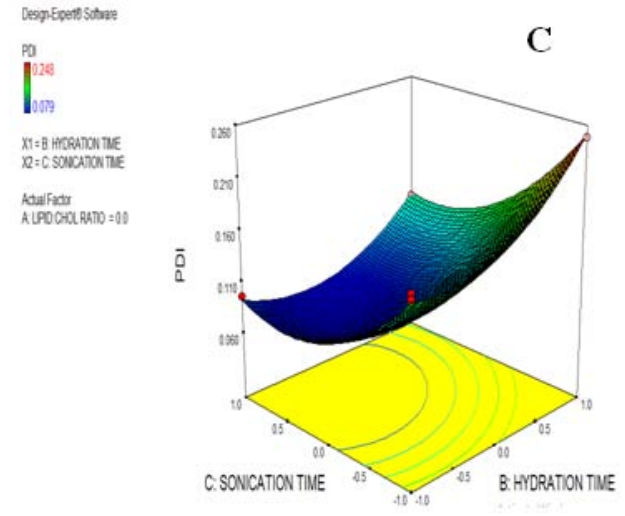

Fig. 4: A-C 3D surface response curves representing PDI

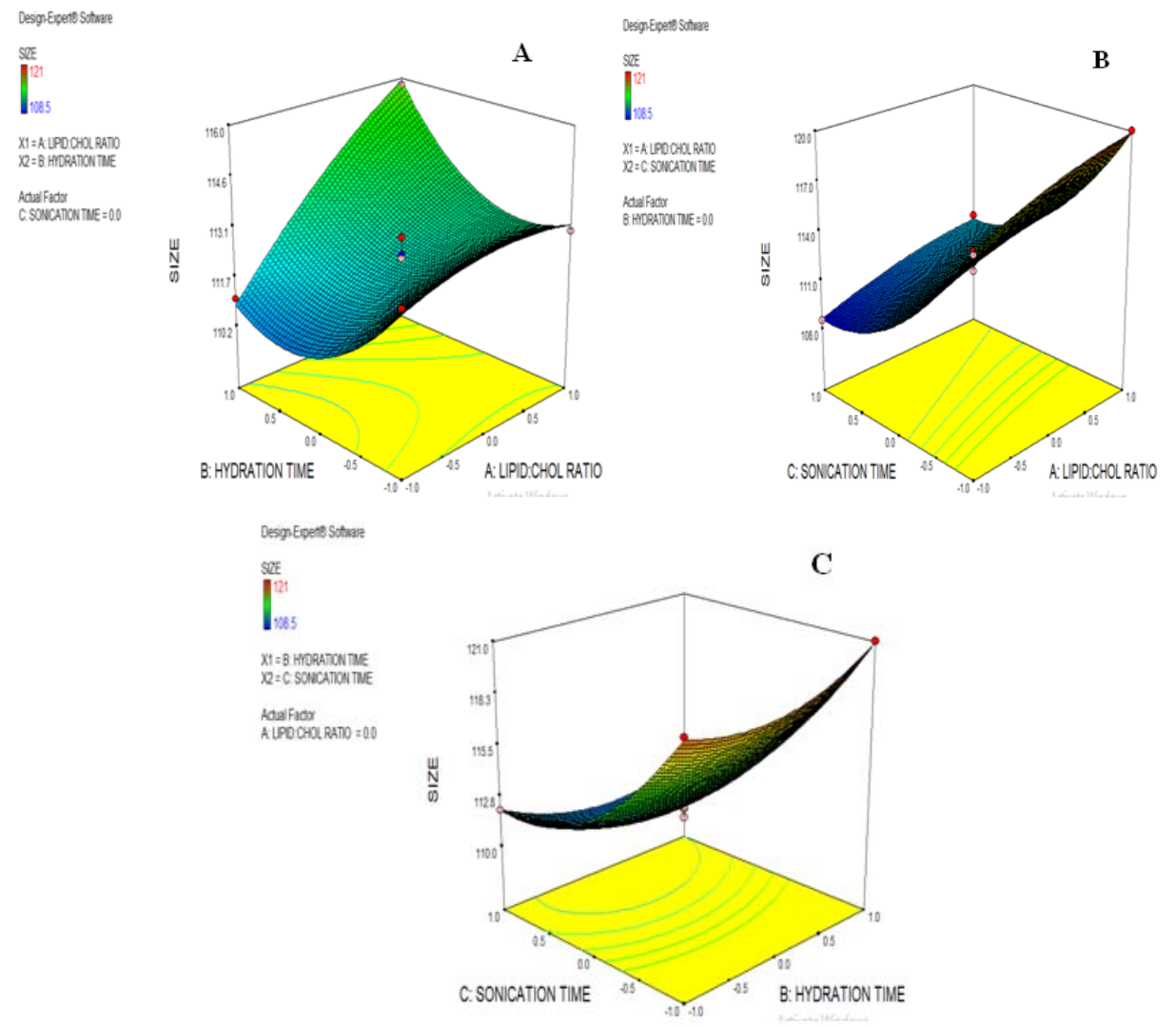

Fig. 5: A-C 3D surface response curves representing the vesicle size,

The cumulative percentage of drug release from Eudragit coated beads is shown in fig. 7. It was found that there was no drug release up to $6 \mathrm{~h}$; it started releasing the drug after the completion of $6.5 \mathrm{~h}$ when these beads came in contact with simulated intestinal fluid $\mathrm{pH}$ 6.8. There was no drug release in the upper parts of GIT i.e. stomach and intestine from Eudragit S-100 coated beads since they were safeguarded in the upper GIT due to the Eudragit-S-100 coating which undergoes dissolution only at $\mathrm{pH}>6.8$. The coating of the beads starts dissolving after reaching the distal part of the small intestine and the polysaccharidase enzyme present in the colon digests the uncoated alginate beads leading to the release of the entrapped liposomes. At the end of 48 $\mathrm{h}, 71.6 \%$ of oxaliplatin was released from the liposomes. The results attained are concordant with those obtained by Chaurasia et al. 2007. They prepared guar gum microspheres bearing methotrexate and reported that maximum drug release was observed after $7 \mathrm{~h}$, which is due to the digestion of guar gum by the colonic microflora [28].

Swelling is an essential characteristic that determines the release behavior of a drug molecule. The swelling property of the beads was determined in buffer solutions with $\mathrm{pH} 1.2$ and 7.4 (fig. 8). It is noticed that the swelling property of beads is highly affected by the $\mathrm{pH}$ of the medium. The degree of swelling of the beads was found to be higher at $\mathrm{pH} 7.4$ than at $\mathrm{pH}$ 1.2. It could also be due to the ion exchange reaction between $\mathrm{Na}^{+}$ions of the phosphate buffer and $\mathrm{Ca}^{2+}$ ions linked to carboxylic acid groups of alginate. Monovalent ions substitute bivalent ions, break the "egg-box" structure and increase the distance between the polymer chains, thereby enhancing the fluid absorption and swelling of the beads. The outcomes were according to the study reported by Seeli et al. 2016 in which they developed guar gum succinate sodium alginate beads that depicted pH-dependent swelling property [29]. 


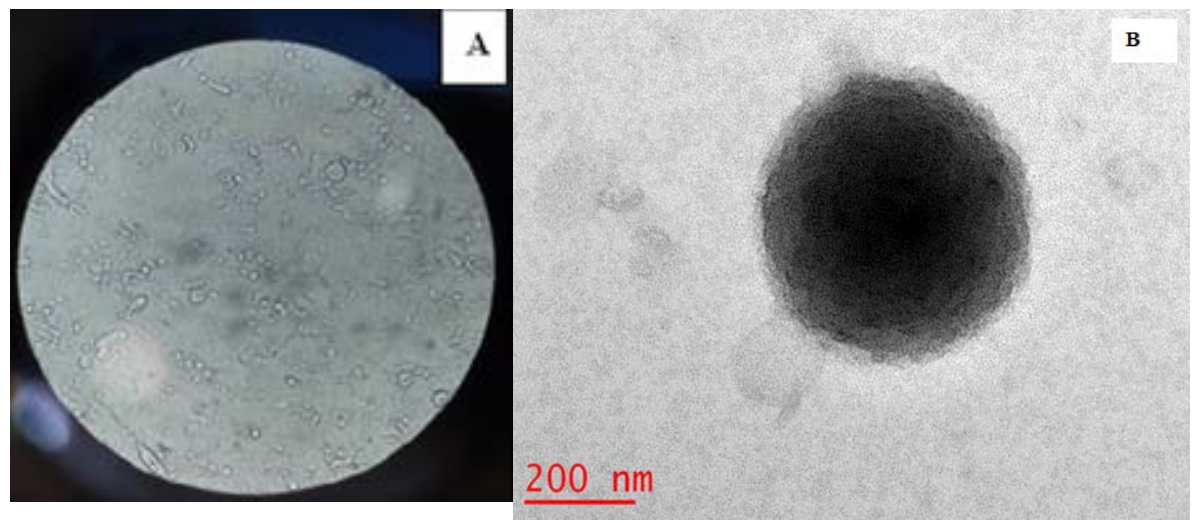

Fig. 6: Images of liposomes (A) Phase-contrast photomicrographs (40x) (B) TEM image

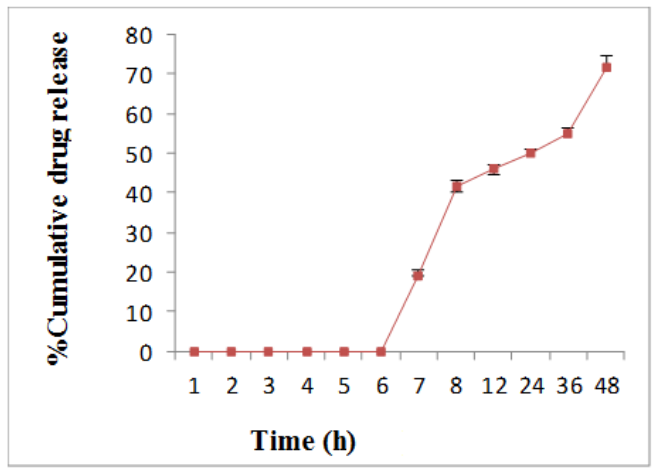

Fig. 7: In vitro drug release profile of eudragit coated beads bearing liposomes in various simulated fluids. Simulated gastric fluid (pH 1.2); simulated intestinal fluid (pH 4.5), simulated colon fluid ( $\mathrm{pH}$ 6.8). Results are presented as mean $\pm S D, n=3$

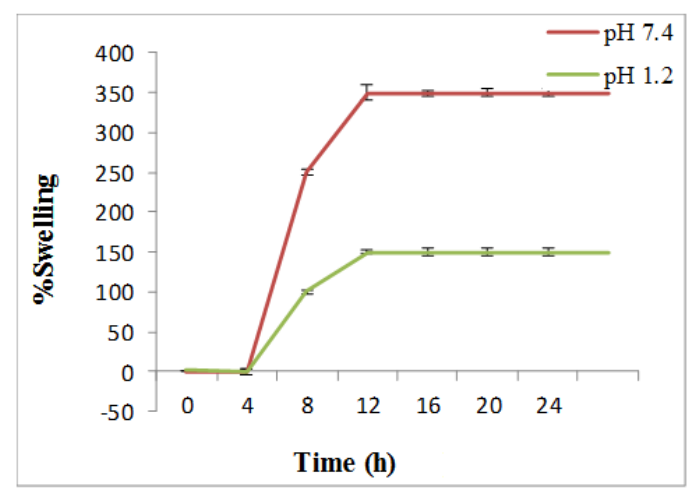

Fig. 8: Determination of \% swelling of alginate beads at pH 1.2 and $\mathrm{pH}$ 7.4. Results are presented as mean $\pm S D, n=3$

\section{CONCLUSION}

In the current study, oxaliplatin-loaded liposomes were formulated using the thin-film hydration method followed by successful optimization using BBD. They were entrapped in alginate beads and dip-coated with Eudragit S-100. The oral delivery of the developed eudragit S-100 coated beads encapsulating oxaliplatin-loaded liposomes can proffer high protection from premature drug release in simulated upper parts of GIT. Whereas, the beads delivered most of the drug in the colon, an environment, abundant in bacterial enzymes that digest the alginate and permit the drug release in the colon. Therefore, the developed system has immense potential in the localized delivery of chemotherapeutic drugs in the colon.

\section{ACKNOWLEDGEMENT}

The authors are sincerely thankful to M/s Khandelwal Laboratories Ltd., Mumbai, India, for gifting L-OHP, They are also thankful to DSTFIST and DST PHASE-II PURSE for providing an instrumentation facility.

\section{FUNDING}

This work was funded by the Indian Council of Medical Research New Delhi, India (Ref. no. 45/7/2018-Nan/BMS)

\section{AUTHORS CONTRIBUTIONS}

Tiwari A: Conducted all the experiments, collected and analyzed the data. Wrote the paper

Jain SK: Designed and supervised the experiments.

\section{CONFLICT OF INTERESTS}

Authors have no conflict of interest.

\section{REFERENCES}

1. Siegel R, DeSantis C, Jemal A. Colorectal cancer statistics, 2014. CA Cancer J Clin. 2014;64(2):104-17. doi: 10.3322/caac.21220, PMID 24639052.

2. Gupta S, Provenzale D, Regenbogen SE, Hampel H, Slavin TP, Hall MJ, Llor X, Chung DC, Ahnen DJ, Bray T, Cooper G, Early DS, Ford JM, Giardiello FM, Grady W, Halverson AL, Hamilton SR, Klapman JB, Larson DW, Lazenby AJ, Lynch PM, Markowitz AJ, Mayer RJ, Ness RM, Samadder NJ, Shike M, Sugandha S, Weiss JM, Dwyer MA, Ogba N. NCCN guidelines insights: Genetic/Familial high-risk assessment: Colorectal, version 3.2017. J Natl Compr Canc. 2017;15(12):1465-75. doi: 10.6004/jnccn.2017.0176, PMID 29223984.

3. Fong CW. Platinum anti-cancer drugs: free radical mechanism of Pt-DNA adduct formation and anti-neoplastic effect. Free Radic Biol Med. 2016;95:216-29. doi: 10.1016/j.freeradbiomed.2016.03.006, PMID 27012421.

4. BH JG, Shankar S, Munisamy M, RS A, Sagar V. Development of pH-dependent chronomodulated delivery systems of 5fluorouracil and oxaliplatin to treat colon cancer. Int J Appl Pharm. 2020;12(5):118-30.

5. Perego P, Robert J. Oxaliplatin in the era of personalized medicine: from mechanistic studies to clinical efficacy. Cancer Chemother Pharmacol. 2016;77(1):5-18. doi: 10.1007/s00280015-2901-x, PMID 26589793.

6. Torchilin VP. Recent advances with liposomes as pharmaceutical carriers. Nat Rev Drug Discov. 2005;4(2):14560. doi: 10.1038/nrd1632, PMID 15688077.

7. Atara SA, Soniwala MM. Formulation and evaluation of pectincalcium chloride beads of azathioprine for colon targeted drug delivery system. Int J Pharm Pharm Sci. 2018;10(1):172-9. doi: 10.22159/ijpps.2018v10i1.23175. 
8. Ramanathan M, Subramanian L. Formulation and evaluation of colon targeted matrix tablets of ibuprofen. Asian J. Pharm. Res Dev. 2018;6(2):9-19.

9. Madhavi C, Babu PK, Maruthi Y, Parandhama A, Reddy OS, Rao KC, Subha Mcs, Kumar RJ. Sodium alginate-locust bean gum IPN hydrogel beads for the controlled delivery of nimesulideanti-inflammatory drug. Int J Pharm Pharm Sci. 2017;9(10):245-52. doi: 10.22159/ijpps.2017v9i10.20231.

10. Ferreira SL, Bruns RE, Ferreira HS, Matos GD, David JM, Brandao GC, da Silva EG, Portugal LA, dos Reis PS, Souza AS, dos Santos WN. Box-Behnken design: an alternative for the optimization of analytical methods. Anal Chim Acta 2007;597(2):179-86. doi: 10.1016/j.aca.2007.07.011, PMID 17683728.

11. Bangham AD. Membrane models with phospholipids. Prog Biophys Mol Biol. 1968;18:29-95. doi: 10.1016/00796107(68)90019-9, PMID 4894874.

12. Mezei M, Gulasekharam V. Liposomes- a selective drug delivery system for the topical route of administration: gel dosage form J Pharm Pharmacol. 1982;34(7):473-4. doi: 10.1111/j.20427158.1982.tb04767.x, PMID 6126554.

13. Alagumurthi N, Palaniradja K, Soundararajan V. Optimization of grinding process through design of experiment (DOE)- A comparative study. Mater Manuf Processes. 2006;21(1):19-21. doi: 10.1080/AMP-200060605.

14. Giovanni M. Response surface methodology and product optimization. Food Technol. 1983.

15. Saraf S, Jain A, Tiwari A, Verma A, Jain SK. Engineered liposomes bearing camptothecin analogue for tumour targeting: in vitro and ex-vivo studies. J Liposome Res. 2020 Aug 11:1-16. doi: 10.1080/08982104.2020.1801725, PMID 32718195

16. Galpin IJ, Kenner GW, Ohlsen SR, Ramage R. Gel filtration of protected peptides on Sephadex G-50 in hexamethylphosphoramide containing 5\% water. J Chromatogr. 1975;106(1):125-9. doi: 10.1016/s00219673(01)81054-2, PMID 1150783.

17. Jain A, Jain SK, Ganesh N, Barve J, Beg AM. Design and development of ligand-appended polysaccharidic nanoparticles for the delivery of oxaliplatin in colorectal cancer. Nanomedicine. 2010;6(1):179-90. doi: 10.1016/j.nano.2009.03.002, PMID 19447205.

18. Xing L, Dawei C, Liping X, Rongqing Z. Oral colon-specific drug delivery for bee venom peptide: development of a coated calcium alginate gel beads-entrapped liposome. J Control
Release. 2003;93(3):293-300. doi: 10.1016/j.jconrel. 2003.08.019, PMID 14644579.

19. Huyghebaert N, Vermeire A, Remon JP. In vitro evaluation of coating polymers for enteric coating and human ileal targeting. Int J Pharm. 2005;298(1):26-37. doi: 10.1016/ j.ijpharm.2005.03.032, PMID 15894443.

20. Xie Cl, Lee SS, Choung S, Kang SS, Choi YJ. Preparation and optimisation of liposomein-alginate beads containing oyster hydrolysate for sustained release. Int J Food Sci Technol. 2016;51(10):2209-16. doi: 10.1111/ijfs.13207.

21. Lee BJ, Min GH. Preparation and release characteristics of polymer-reinforced and coated alginate beads. Arch Pharm Res. 1995;18(3):183-8. doi: 10.1007/BF02979193.

22. Souder J, Ellenbogen W. Control of d-amphetamine sulphate sustained release capsule. Drug Stand. 1985;26:77-9.

23. Segale L, Giovannelli L, Mannina P, Pattarino F. Calcium alginate and calcium alginate-chitosan beads containing celecoxib solubilized in a self-emulsifying phase. Scientifica. 2016;2016:5062706. doi: 10.1155/2016/5062706, PMID 27127680 .

24. Wang T, Jiang Y, Chu H, Liu X, Dai Y, Wang D. Doxorubicin and lovastatin co-delivery liposomes for synergistic therapy of liver cancer. J Drug Deliv Sci Technol. 2019;52:452-9. doi 10.1016/j.jddst.2019.04.045.

25. Yang S, Chen J, Zhao D, Han D, Chen X. Comparative study on preparative methods of DC-Chol/DOPE liposomes and formulation optimization by determining encapsulation efficiency. Int J Pharm. 2012;434(1-2):155-60. doi: 10.1016/j.ijpharm.2012.05.041, PMID 22643228.

26. Narayan R, Singh M, Ranjan O, Nayak Y, Garg S, Shavi GV, Nayak UY. Development of risperidone liposomes for brain targeting through intranasal route. Life Sci. 2016;163:38-45. doi: 10.1016/j.lfs.2016.08.033, PMID 27593571.

27. Kumari A, Jain A, Hurkat P, Tiwari A, Jain SK. Eudragit S100 coated microsponges for colon targeting of prednisolone. Drug Dev Ind Pharm. 2018;44(6):902-13. doi: 10.1080/03639045.2017.1420079, PMID 29260916.

28. Chaurasia M, Chourasia MK, Jain NK, Jain A, Soni V, Gupta Y, Jain SK. Cross-linked guar gum microspheres: A viable approach for improved delivery of anticancer drugs for the treatment of colorectal cancer. AAPS PharmSciTech. 2006;7(3):74. doi: 10.1208/pt070374, PMID 17025254.

29. Seeli DS, Dhivya S, Selvamurugan N, Prabaharan M. Guar gum succinate-sodium alginate beads as a $\mathrm{pH}$-sensitive carrier for colon-specific drug delivery. Int J Biol Macromol. 2016;91:4550. doi: 10.1016/j.ijbiomac.2016.05.057, PMID 27212216. 